\title{
Article
}

\section{Transient Receptor Potential Ankyrin 1 (TRPA1)—An Inflammation-Induced Factor in Human HaCaT Keratinocytes}

\author{
Samu Luostarinen, Mari Hämäläinen and Eeva Moilanen *(D) \\ The Immunopharmacology Research Group, Faculty of Medicine and Health Technology, Tampere University \\ and Tampere University Hospital, 33014 Tampere, Finland; samu.luostarinen@tuni.fi (S.L.); \\ mari.hamalainen@tuni.fi (M.H.) \\ * Correspondence: eeva.moilanen@tuni.fi
}

check for updates

Citation: Luostarinen, S.; Hämäläinen, M.; Moilanen, E. Transient Receptor Potential Ankyrin 1 (TRPA1)—An InflammationInduced Factor in Human HaCaT Keratinocytes. Int. J. Mol. Sci. 2021, 22, 3322. https://doi.org/10.3390/ ijms22073322

Academic Editors: Viktorie Vlachova and Peter M. Zygmunt

Received: 8 February 2021

Accepted: 17 March 2021

Published: 24 March 2021

Publisher's Note: MDPI stays neutral with regard to jurisdictional claims in published maps and institutional affiliations.

Copyright: (c) 2021 by the authors. Licensee MDPI, Basel, Switzerland. This article is an open access article distributed under the terms and conditions of the Creative Commons Attribution (CC BY) license (https:/ / creativecommons.org/licenses/by/ $4.0 /)$.

\begin{abstract}
Transient receptor potential ankyrin 1 (TRPA1) is an ion channel mainly studied in sensory neurons where it mediates itch, pain and neurogenic inflammation. Recently, some nonneuronal cells have also been shown to express TRPA1 to support inflammatory responses. To address the role of TRPA1 in skin inflammation, we aimed to investigate TRPA1 expression in keratinocytes. HaCaT cells (a model of human keratinocytes) and skin biopses from wild-type and TRPA1 deficient mice were used in the studies. TRPA1 expression in nonstimulated keratinocytes was very low but significantly inducible by the proinflammatory cytokine tumor necrosis factor (TNF) in an nuclear factor kappa $\mathrm{B}(\mathrm{NF}-\mathrm{kB})$, and mitogen-activated protein (MAP) kinase (p38 and c-Jun N-terminal kinase, JNK)dependent manner. Interestingly, drugs widely used to treat skin inflammation, the calcineurin inhibitors tacrolimus and cyclosporine and the glucocorticoid dexamethasone, significantly decreased TRPA1 expression. Furthermore, pharmacological inhibition and genetic deletion of TRPA1 reduced the synthesis of TNF-induced monocyte chemoattractant protein 1 (MCP-1) in keratinocytes and mouse skin biopsies. In conclusion, these findings point to an inflammatory role for TRPA1 in keratinocytes and present TRPA1 as a potential drug target in inflammatory skin diseases.
\end{abstract}

Keywords: transient receptor potential ankyrin 1 (TRPA1) cation channel; inflammation; tumor necrosis factor (TNF); calcineurin inhibitors; glucocorticoids

\section{Introduction}

Transient Receptor Potential Ankyrin 1 (TRPA1) is an ion channel localized to the plasma membrane. It mediates ion currents, mainly $\mathrm{Ca}^{2+}$ and $\mathrm{Na}^{+}$, but also other cations such as $\mathrm{Zn}^{2+}$. [1] Previously, the majority of research has focused on TRPA1 in sensory neurons. Indeed, TRPA1 expression is well characterized in A $\delta$ and C-type fibers, where it functions mediating pain and hyperalgesia [2,3]. The main physiological function of TRPA1 is believed to be a neuronal chemosensor, sensing and responding to noxious compounds [1]. In addition, TRPA1 has been shown to participate in the generation of neurogenic inflammation in sensory neurons where elevation of intracellular calcium levels through TRPA1 activation promotes exocytosis of proinflammatory neuropeptides [4]. TRPA1 expression has been characterized also in some nonneuronal cells such as synoviocytes [5] and chondrocytes [6]. In these cells, TRPA1 has been shown to promote inflammatory responses $[5,6]$ but its physiological functions in nonneuronal cells remain unclear.

TRPA1 is activated by various stimuli, including chemical, mechanical and thermal irritation [7]. Of these functions, the chemosensory function of TRPA1 is best characterized. Indeed, the list of known TRPA1 ligands is rather long, including exogenous and endogenous compounds. The exogenous activators include substances such as allyl isothiocyanate (AITC) [8] from mustard oil and allicin [9] from garlic. Interestingly, the endogenous TRPA1 activator compounds include inflammation associated factors, particularly reactive oxygen (ROS) and nitrogen (RNS) species and their derivatives [7,10-13]. In addition, 
TRPA1 modulation extends to indirect sensitization via $G$ protein-coupled receptor (GPCR) pathways. For example, the inflammatory mediators bradykinin and prostaglandin $\mathrm{E}_{2}$, and the proteases trypsin and tryptase, via their respective GPCRs, sensitize TRPA1 through activating the intracellular protein kinase A (PKA) and phospholipase C (PLC) signaling pathways [14-16]. PKA sensitizes TRPA1 through direct phosphorylation of certain TRPA1 amino acid residues [17], while PLC seems to mainly act via depleting phosphatidylinositol 4,5-bisphosphate (PIP2), which is known to inhibit TRPA1 [15].

TRPA1 activation by exogenous or endogenous agonists has been reported to induce and/or support inflammation in various models. Topical application of AITC is known to induce inflammation in a TRPA1-dependent manner as judged by pharmacological and genetic evidence $[3,18]$. TRPA1-mediated inflammation has also been observed in carrageenan-induced paw edema [19] and urate crystal [20,21] and monosodiumiodoacetate (MIA)-induced arthritis [22]. TRPA1 may also be involved in some inflammatory skin disorders, as neurogenic inflammation is known to play a role in cutaneous inflammation [4]. In addition, TRPA1 has been reported to promote the inflammatory response and itch in models of allergic contact dermatitis, atopic dermatitis and cytokine-induced itch [23-27], while a protective role has been suggested for TRPA1 in the imiquimodinduced model of psoriasiform dermatitis [28].

Although TRPA1 expression in human keratinocytes has been reported [29,30], not much is known about the underlying mechanisms. As TRPA1 seems to have a significant role in models of inflammatory skin conditions such as atopic dermatitis and allergic contact dermatitis, and keratinocytes contribute to the pathogenesis of these skin conditions, we aimed to study TRPA1 expression in human HaCaT keratinocytes exposed to inflammatory stimuli.

\section{Results}

\subsection{TRPA1 Expression Is Enhanced by TNF in Human HaCaT Keratinocytes}

In basal conditions, TRPA1 expression in HaCaT keratinocytes was barely measurable by RT-PCR. When tumor necrosis factor (TNF) was added into the culture, TRPA1 expression was enhanced in a dose and time-dependent manner (Figure 1). The effect of other inflammatory factors, namely IL-1 $\beta(100 \mathrm{pg} / \mathrm{mL})$, LPS $10(\mathrm{ng} / \mathrm{mL})$, resistin $(1 \mu \mathrm{g} / \mathrm{mL})$, leptin $(10 \mu \mathrm{g} / \mathrm{mL})$, IL-6 (100 ng/mL), IL-13 $(10 \mathrm{ng} / \mathrm{mL})$ and IFN- $\gamma(10 \mathrm{ng} / \mathrm{mL})$, on TRPA1 expression was also studied, but statistically significant upregulation of TRPA1 expression was not observed.

To confirm TRPA1 expression at the protein level, we carried out Western blot analyses using HEK-293 cells transfected with the human TRPA1 plasmid as a positive control. TRPA1 protein expression was upregulated in $\mathrm{HaCaT}$ cells stimulated with TNF but not detectable in unstimulated cells. (Figure 1C).

In addition, the functionality of the TRPA1 ion channel was investigated using the Fluo 3-AM intracellular $\mathrm{Ca}^{2+}$ measurement. $\mathrm{HaCaT}$ cells were cultured with or without TNF $(20 \mathrm{ng} / \mathrm{mL})$ for $24 \mathrm{~h}$. Thereafter, the cells were preincubated with or without the TRPA1 blocker HC-030031 $(100 \mu \mathrm{M})$ for $30 \mathrm{~min}$ before the TRPA1 agonist AITC $(50 \mu \mathrm{M})$ was applied. We detected a significant increase in intracellular $\mathrm{Ca}^{2+}$ concentration upon AITC application in cells cultured with TNF, which was completely reversible by HC-030031 treatment, indicating that TNF increases the expression of functional TRPA1 channel (Figure 1D,E). 


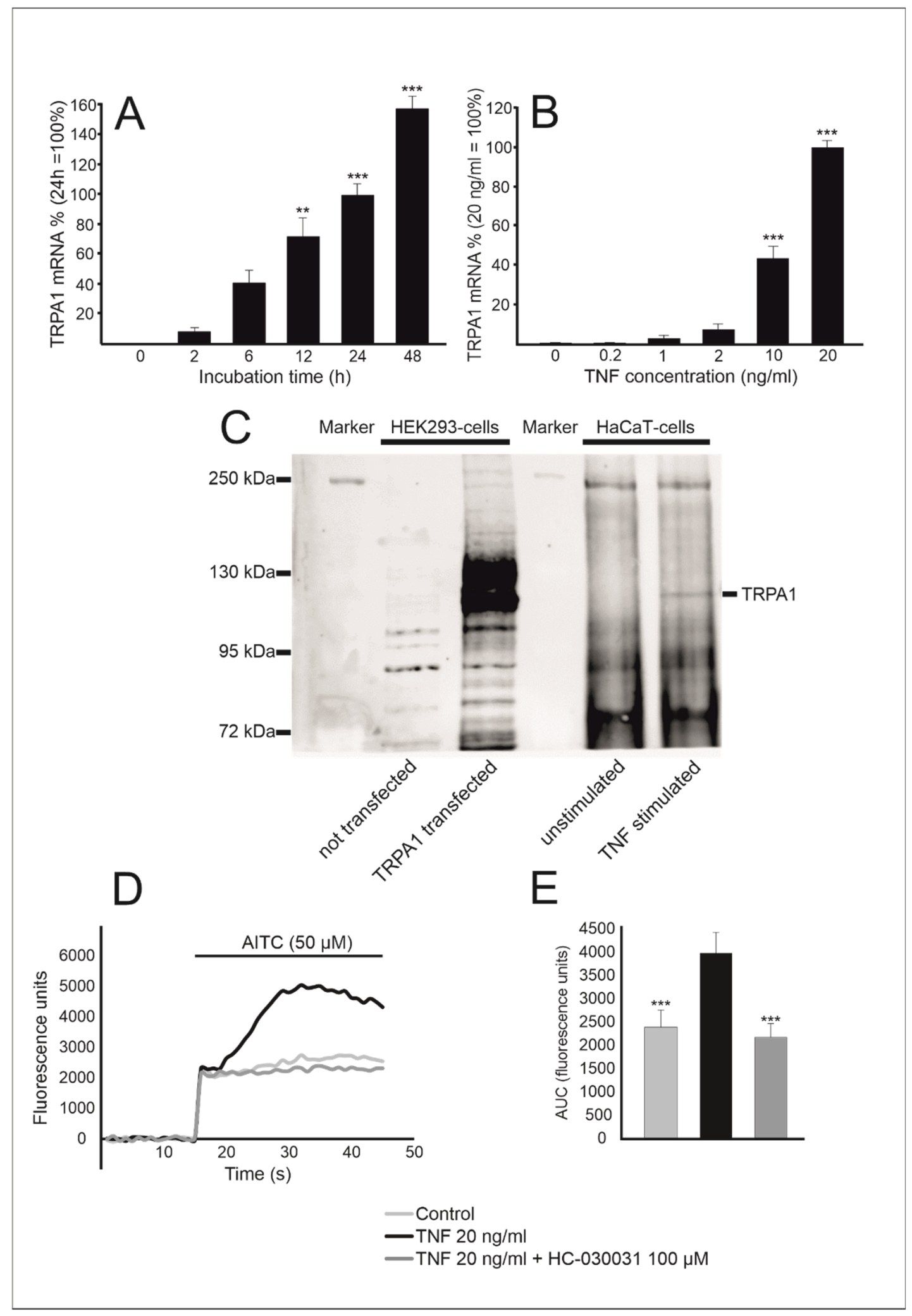

Figure 1. Tumor necrosis factor (TNF) induces transient receptor potential ankyrin 1 (TRPA1) expression in human HaCaT keratinocytes in a time and dose-dependent manner. HaCaT cells were stimulated with TNF $(20 \mathrm{ng} / \mathrm{mL})$ for indicated times (A) or with an increasing concentration of TNF (from $0.2 \mathrm{ng} / \mathrm{mL}$ to $20 \mathrm{ng} / \mathrm{mL}$ ) for $24 \mathrm{~h}$ (B). Thereafter total RNA was extracted 
and TRPA1 expression was measured by RT-PCR. Results were normalized against GAPDH mRNA. TRPA1 mRNA level at $24 \mathrm{~h} \mathrm{(A)} \mathrm{and} \mathrm{with} 20 \mathrm{ng} / \mathrm{mL}$ (B) was set as 100\% and the other values are given in relation to that value. Results are expressed as mean + SEM, $n=4$. Statistical significance was calculated against $2 \mathrm{~h}(\mathrm{~A})$ or control without added TNF (B) using one-way ANOVA with Bonferroni's post-test. ${ }^{* *}=p<0.01,{ }^{* * *}=p<0.001$. In (C), HaCaT keratinocytes were cultured with TNF $(20 \mathrm{ng} / \mathrm{mL})$ for $48 \mathrm{~h}$. After protein extraction and immunoprecipitation, TRPA1 protein (indicated in image) was detected using Western blotting. HEK293 cells transfected with human TRPA1 plasmid were used as a positive control. The blot is a representative of three distinct experiments with similar results. In (D,E) is shown that TNF-treated HaCaT-cells exhibited a robust intracellular $\mathrm{Ca}^{2+}$ increase in response to allyl isothiocyanate (AITC) stimulation, effectively inhibited by HC-030031, suggesting that the upregulated TRPA1 is functional. Intracellular $\mathrm{Ca}^{2+}$ levels were measured utilizing the $\mathrm{Ca}^{2+}$ indicator Fluo 3-AM. HaCaT keratinocytes were cultured with or without TNF $(20 \mathrm{ng} / \mathrm{mL})$ for $24 \mathrm{~h}$. Thereafter, the cells were incubated in the presence or absence of the TRPA1 antagonist HC-030031 (100 $\mu \mathrm{M})$ for 30 min before the TRPA1 agonist AITC $(50 \mu \mathrm{M})$ was applied and measurements were continued for $30 \mathrm{~s}$. In (D) is shown a representative measurement, and in (E) area under curve analysis of the experiment in (D) is presented. Results in (E) are expressed as mean + SEM, $n=8$. Statistical significance was calculated against cells cultured with TNF and measured in the absence of HC-030031 using one-way ANOVA with Bonferroni's post-test, ${ }^{* * *}=p<0.001$.

\subsection{TRPA1 Expression Is Upregulated by NF- $\kappa B$ and MAP Kinase Pathways}

After observing the increased expression of TRPA1 in response to TNF, we continued by studying which intracellular signaling pathways relevant to inflammation might contribute to TRPA1 upregulation under TNF stimulation. The pharmacological inhibitors MG132 and pyrrolidinedithiocarbamate ammonium (PDTC), c-Jun N-terminal kinase (JNK) inhibitor VIII and SB 203580 were used to study the role of nuclear factor kappa B (NF-kB), and JNK and p38 MAP kinases, respectively. Both NF-kB inhibitors MG132 and PDTC inhibited TNF-induced TRPA1 expression. In addition, JNK inhibitor VIII and SB 203580 had a statistically significant inhibitory effect on TNF-induced TRPA1 expression, indicating a role for NF- $\mathrm{B}$ as well as JNK and p38 MAP kinases in upregulating TRPA1 in these cells (Figure 2).

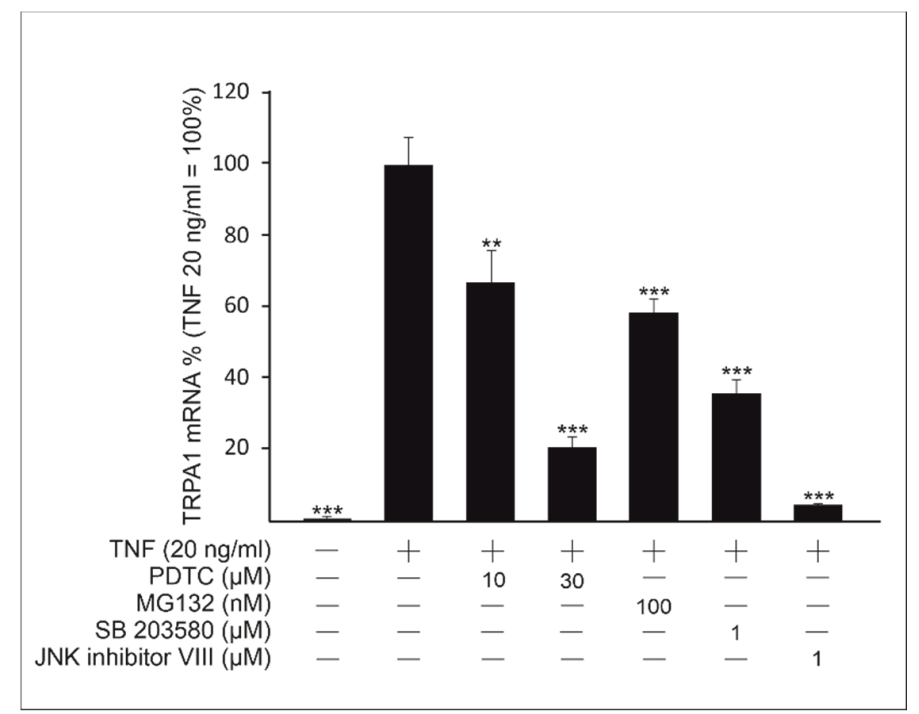

Figure 2. Transient receptor potential ankyrin 1 (TRPA1) upregulation by tumor necrosis factor (TNF) is mediated by nuclear factor kappa B (NF-kB), and p38 and c-Jun N-terminal kinase (JNK) mitogenactivated protein kinase (MAPK) pathways. TRPA1 expression was induced by TNF (20 ng/mL), and pharmacological inhibitors of the signaling routes were applied. p38 MAPK inhibitor SB 203580 $(1 \mu \mathrm{M})$, JNK inhibitor VIII $(1 \mu \mathrm{M})$ and NF- $\mathrm{BB}$ inhibitors MG132 (100 nM) and pyrrolidinedithiocarbamate ammonium (PDTC; 10 and $30 \mu \mathrm{M}$ ) were used. Incubations were continued for $24 \mathrm{~h}$, after which total RNA was isolated and TRPA1 expression was measured using RT-PCR. Results were normalized against GAPDH mRNA. TNF-induced TRPA1 expression in the absence of the signaling inhibitors was set as $100 \%$ and the other values are given in relation to that value. Results are expressed as mean + SEM, $n=4$. Statistical significance was calculated against cells stimulated with TNF only using one-way ANOVA with Bonferroni's post-test. ${ }^{* *}=p<0.01,{ }^{* * *}=p<0.001$. 


\subsection{The Immunosuppressive Drugs Dexamethasone, Cyclosporine and Tacrolimus Inhibit TNF-Induced TRPA1 Expression}

As TRPA1 was shown to be induced by the key inflammatory cytokine TNF, and its expression was mediated via inflammatory signaling pathways, we aimed to investigate whether immunosuppressive drugs affect TRPA1 expression. Effects of the calcineurin/nuclear factor of activated T-cells (NFAT) pathway inhibitors cyclosporine and tacrolimus, and the potent glucocorticoid dexamethasone, drugs widely used in the treatment of inflammatory skin conditions, were studied. Interestingly, we found that both cyclosporine and tacrolimus significantly inhibited TNF-induced TRPA1 upregulation (Figure 3). Dexamethasone was also found to inhibit TRPA1 expression (Figure 3).

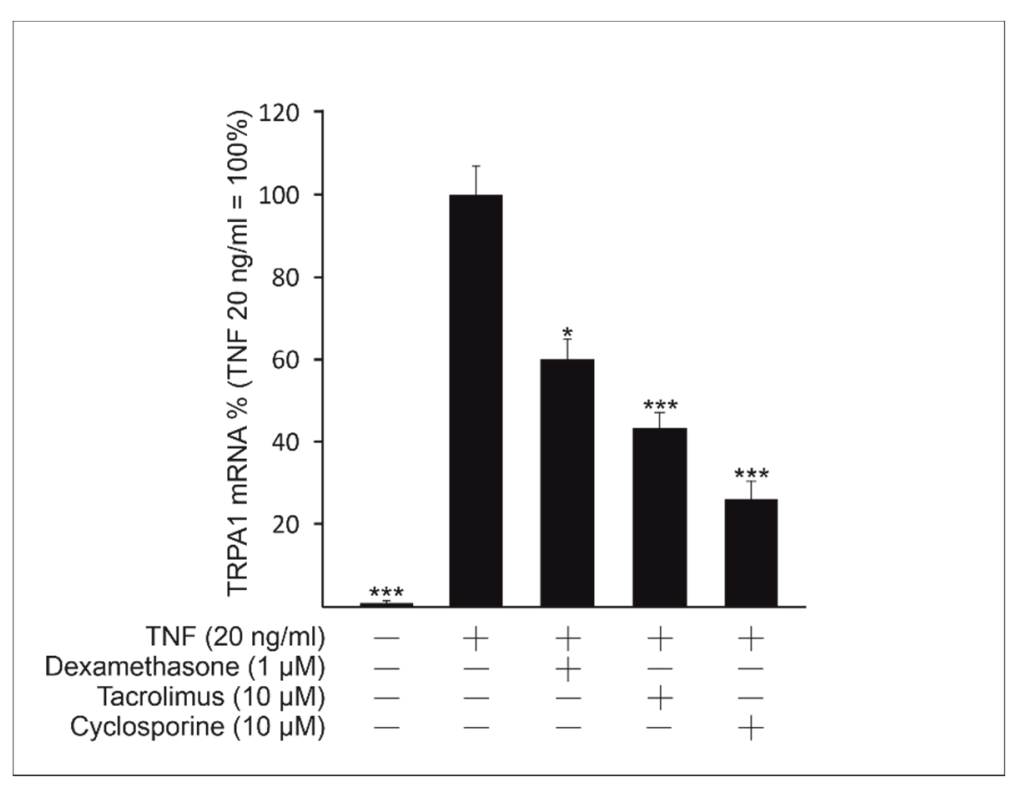

Figure 3. Dexamethasone and calcineurin/nuclear factor of activated T-cells (NFAT) inhibitors cyclosporine and tacrolimus inhibit transient receptor potential ankyrin 1 (TRPA1) expression under tumor necrosis factor (TNF) stimulation. HaCaT cells were cultured with TNF in the absence or in the presence of the drugs tested for $24 \mathrm{~h}$. Thereafter total mRNA was extracted and TRPA1 expression was measured using RT-PCR. Results were normalized against GAPDH mRNA. TNF-induced TRPA1 expression in the absence of the tested drugs was set as $100 \%$ and the other values are given in relation to that value. Results are expressed as mean + SEM, $n=4$. Statistical significance was calculated against cells stimulated with TNF only using one-way ANOVA with Bonferroni's post-test. ${ }^{*}=p<0.05,{ }^{* * *}=p<0.001$.

\subsection{TRPA1 Mediates the Production of the Chemokine MCP-1 in TNF-Stimulated HaCaT Cells} and in Mouse Skin Ex Vivo

To preliminarily assess the effects of TRPA1 in the skin, we measured the production of monocyte chemoattractant protein 1 (MCP-1) in the HaCaT keratinocyte culture and in ex vivo mouse skin sample supernatants. Interestingly, significantly decreased MCP-1 levels were found in the cell cultures under treatment with the TRPA1 antagonist HC-030031 as compared to stimulation with TNF only. The result was reproduced in mouse skin samples ex vivo, where TNF was found to enhance MCP-1 production in samples from wild type (WT) but not in those from TRPA1 deficient (knockout, KO) mice (Figure 4). 


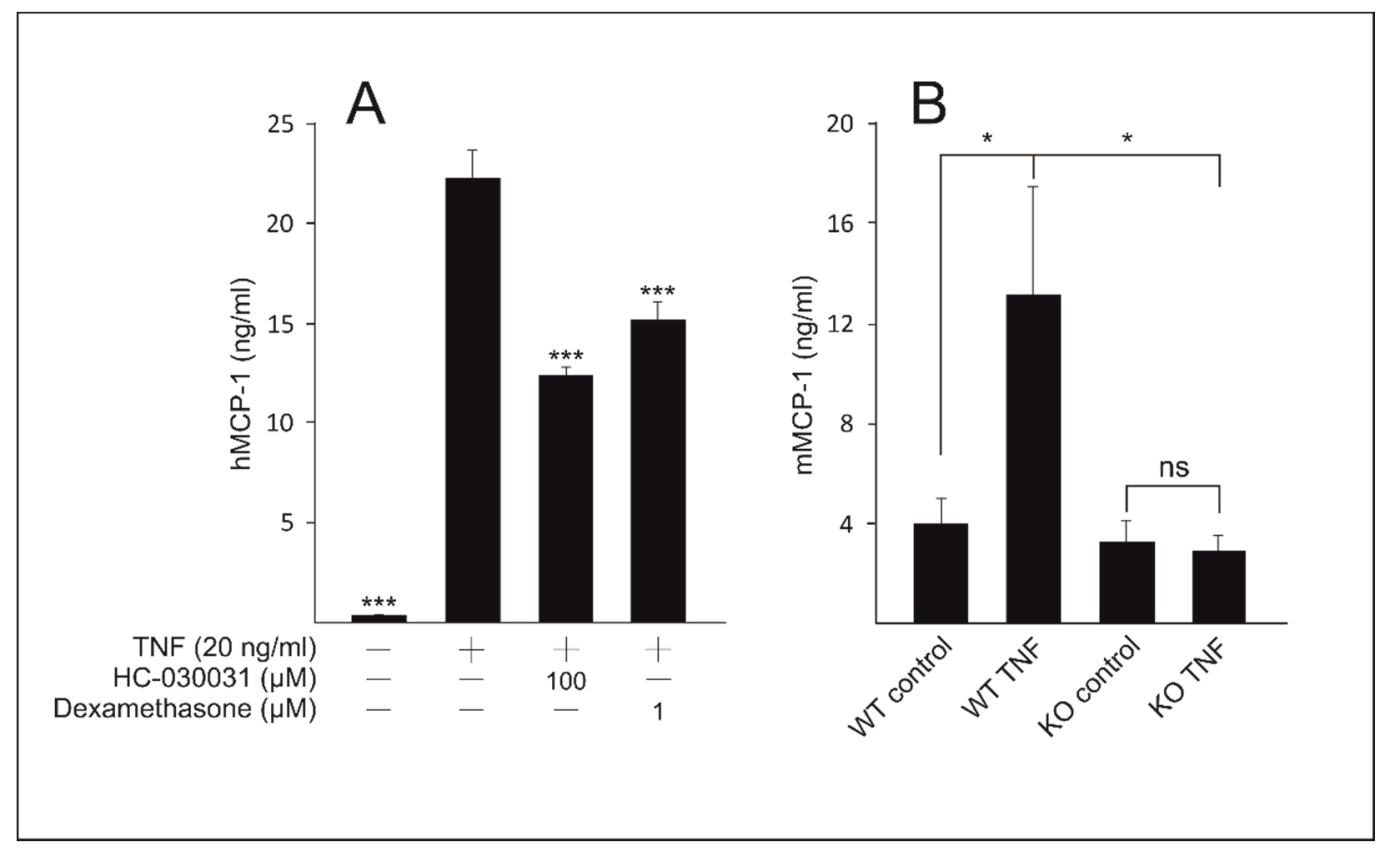

Figure 4. Transient receptor potential ankyrin 1 (TRPA1) mediates tumor necrosis factor (TNF)-induced production of monocyte chemoattractant protein 1 (MCP-1). (A) HaCaT cells were treated with the TRPA1 antagonist HC-030031 (100 $\mu$ M) or the glucocorticoid dexamethasone $(1 \mu \mathrm{M})$ and stimulated with TNF $(20 \mathrm{ng} / \mathrm{mL})$ for $24 \mathrm{~h}$. (B) Skin samples from wild type (WT) and TRPA1 deficient (knockout, KO) mice were stimulated with TNF $(20 \mathrm{ng} / \mathrm{mL})$ for $21 \mathrm{~h}$. MCP-1 concentrations in the culture medium samples were measured by enzyme-linked immunosorbent assay (ELISA). Results are expressed as mean + SEM, $n=4($ A) and $n=4-6$ (B). Statistical significance was calculated against samples stimulated with TNF only using one-way ANOVA with Bonferroni's post-test (A) or in (B) using repeated measures two-way ANOVA with Bonferroni's post-test. ${ }^{*}=p<0.05,{ }^{* * *}=p<0.001$.

\section{Discussion}

The current findings reveal TRPA1 as a potential factor in skin inflammation. TRPA1 expression was barely detectable in basal conditions in human HaCaT keratinocytes but was highly induced by TNF. Further, we found NF- $\mathrm{kB}$, and p38 and JNK MAP kinase pathways to mediate TNF-induced TRPA1 upregulation as judged by pharmacological evidence. Intriguingly, the anti-inflammatory drugs cyclosporine, tacrolimus and dexamethasone (which are all used to treat inflammatory skin diseases) significantly inhibited TNF-induced TRPA1 upregulation. Finally, we found a role for TRPA1 in mediating MCP-1 production in human keratinocytes and ex vivo skin samples of mice, as assessed by immunoassay.

After being first found in human fibroblasts [31], TRPA1 has mainly been investigated in sensory neurons where it is expressed in A $\delta$ and C-fibers [1,32,33]. More recently, TRPA1 has been studied also in non-neuronal cells such as chondrocytes [6] and synoviocytes [5]. A study by Atoyan et al. [30] first implicated TRPA1 expression in human skin. Thereafter, TRPA1 expression in the skin was reported in mast cells [25], melanocytes [34] and keratinocytes [29]. In nonneuronal cells, TRPA1 has been shown to support proinflammatory responses $[25,29,35]$. In addition, TRPA1 has been found to contribute to many preclinical models of inflammatory diseases such as allergic contact dermatitis [24], ovalbumin-induced allergic inflammation [36], carrageenan-induced acute inflammation [19], gout [20,21], osteoarthritis [22] and inflammatory bowel disease [37]. In the present study, we found that TRPA1 is, under basal conditions, barely expressed but strongly inducible by the cytokine TNF in a time and dose-dependent manner in human $\mathrm{HaCaT}$ keratinocytes. These results are supported by the previous observations made by Hatano et al. [5] that TNF induces TRPA1 in human synoviocytes. Of interest is that TNF-blockers are successfully used in the treatment of inflammatory skin diseases such as 
psoriasis [38]. Our finding that TNF significantly enhances TRPA1 expression supports the hypothesis that TRPA1 is an inflammatory factor induced upon inflammation.

Having established TRPA1 expression in human keratinocytes and its upregulation by TNF, we explored the mechanisms of TNF-induced TRPA1 expression in these cells. Indeed, the previous knowledge on intracellular mechanisms mediating TRPA1 upregulation has been scarce and, in keratinocytes, nonexistent. NF-KB is a crucial inflammatory transcription factor induced under inflammatory conditions regulating a number of genes [39]. In the present study, we found that the NF-KB inhibitors PDTC and MG132 significantly inhibited TNF-induced TRPA1 expression in human keratinocytes. These results are supported by observations that the TRPA1 gene promoter includes NF- $\mathrm{kB}$ binding sites, and TNF-induced TRPA1 upregulation is partly mediated via NF- $\mathrm{KB}$ in human synoviocytes [5]. We also found that TNF-induced TRPA1 upregulation is at least partly regulated by the MAP kinase pathways $\mathrm{p} 38$ and JNK, as assessed by experiments utilizing their pharmacological inhibitors SB 203580 and JNK inhibitor VIII, respectively. Both pathways are relevant in inflammation, and their inhibition holds potential for treatment of inflammatory disorders [40]. These findings together suggest that TRPA1 is an inflammation-inducible factor in human $\mathrm{HaCaT}$ keratinocytes.

Calcineurin inhibitors, including cyclosporine and tacrolimus, are a class of immunosuppressive and anti-inflammatory drugs used in the treatment of atopic dermatitis and psoriasis along with their original indication to prevent transplant rejection. Traditionally calcineurin inhibitors were thought to act mainly on T-helper cells and suppress the production of IL-2 and other inflammatory cytokines. [41] More recently, the function of the calcineurin/NFAT pathway has also been established in human keratinocytes, regulating cell growth and differentiation, and cytokine expression, possibly accounting for some of the beneficial effects of these drugs in skin diseases [42-44]. Interestingly, we found here that both cyclosporine and tacrolimus inhibit the inflammatory upregulation of TRPA1 in human keratinocytes, which is a novel finding and may contribute to their pharmacological effects in skin diseases.

Glucocorticoids are topically used widely in inflammatory skin diseases [45]. We observed a significant inhibition of the inflammatory TRPA1 upregulation by the potent glucocorticoid dexamethasone. This is in agreement with our recent findings in chondrocytes [46]. Based on the current discoveries, two different groups of anti-inflammatory compounds, namely glucocorticoids and calcineurin inhibitors, seem to downregulate TRPA1 expression in keratinocytes, potentially accounting for some of their anti-inflammatory effects.

TRPA1 activation leads to cellular influx of cations, especially $\mathrm{Ca}^{2+}$ and $\mathrm{Na}^{+}$. Calcium widely regulates gene expression [47] and, accordingly, TRPA1 activation has been reported to regulate the expression of certain inflammatory factors $[6,20,25,29,30]$. Here we showed that TNF-stimulated human keratinocytes produce decreased amounts of MCP-1 under TRPA1 antagonist (HC-030031) therapy, indicating that TRPA1 supports the production of MCP-1 upon TNF stimulation in these cells. Accordingly, we found that in skin samples from mice, TNF-induced MCP-1 production was significantly lower in TRPA1 KO mice compared to WT mice. MCP-1, also known as chemokine (C-C motif) ligand 2 (CCL2), is a potent chemokine linked to many inflammatory conditions mainly attracting monocytes/macrophages to the inflammatory tissue [48]. Intriguingly, MCP-1 is seen as a major factor also in psoriasis, where keratinocytes are an important source of MCP-1, contributing to lesion formation [49]. Our results are supported by previous results showing that HC-030031 attenuated MCP-1 production in response to urate crystals [20]. Thus, we suggest that TRPA1 supports the production of MCP-1 in keratinocytes in inflammatory conditions, potentially linking TRPA1 to the pathogenesis of psoriasis and other inflammatory conditions of the skin.

Taken together, these results suggest that in homeostatic conditions TRPA1 is barely expressed in human keratinocytes but is induced upon inflammatory conditions via TNF and key inflammatory signaling pathways, while TRPA1 expression is downregulated by 
calcineurin/NFAT inhibitors and the glucocorticoid dexamethasone. Once induced, TRPA1 supports the production of MCP-1. Intriguingly, the present study highlights multiple mechanisms affecting TRPA1 expression that are also modulated by immunosuppressive and anti-inflammatory drugs used in the clinic. Interestingly, TNF-inhibitors have shown efficacy and are successfully used in psoriasis and other inflammatory skin conditions [38]. Calcineurin/NFAT inhibitors are indicated in atopic dermatitis and some other skin diseases [41]. The use of topical glucocorticoids is widespread and effective in inflammatory skin conditions [45]. In addition to our data that TRPA1 is an inflammation-inducible gene and supports inflammatory responses, TRPA1 has been shown to play a role in murine models of allergic contact dermatitis [23,24] and atopic dermatitis [25]. Thus, these findings together point to an inflammatory role for TRPA1 in keratinocytes and present TRPA1 as a potential drug target in inflammatory skin diseases.

\section{Materials and Methods}

\subsection{Cell Culture}

HaCaT cells (Cell Lines Service, Eppelheim, Germany) were cultured according to Wilson et al. [50] in low calcium conditions. During the experiments, the HaCat keratinocytes were treated with tumor necrosis factor-alpha (TNF) (R\&D Systems Europe Ltd., Abingdon, UK), PDTC (Sigma-Aldrich, St. Louis, MO, USA), MG 132 (Tocris Bioscience, Bristol, UK), JNK inhibitor VIII (Calbiochem, San Diego, CA, USA), SB 203580 (Tocris Bioscience, Bristol, UK), dexamethasone (Orion corp., Espoo, Finland), tacrolimus (Calbiochem, San Diego, CA, USA), cyclosporine (Calbiochem, San Diego, CA, USA), HC-030031 (Sigma-Aldrich, St. Louis, MO, USA), or with their combinations as indicated.

Human embryonic kidney cells (HEK-293, American Type Culture Collection, Manassas, VA, USA) were cultured and transfected with human TRPA1 plasmid DNA (pCMV6XL4 from Origene, Rockville, MD, USA) as described previously [6]. In brief, the cells were seeded in 6-well plates $\left(1.2 \times 10^{6}\right.$ cells $/$ well $) 24 \mathrm{~h}$ prior to transfection. Cells were transfected for $16 \mathrm{~h}$ with $6 \mu \mathrm{g} /$ well of human TRPA1 plasmid DNA using Lipofectamine 2000 (10 $\mu \mathrm{L} / \mathrm{mL}$; Invitrogen/Life Technologies, Carlsbad, CA, USA).

\subsection{Animals}

Wild type (WT) and TRPA1 deficient (knockout, KO) female B6; 129P-Trpa1(tm1$\mathrm{Kykw}$ )/J mice (Charles River Laboratories, Sulzfeld, Germany) were used in mouse skin sample experiments. Mice were housed under standard conditions (12-12 h light-dark cycle, temperature $22 \pm 1{ }^{\circ} \mathrm{C}$, and humidity 50-60\%) with food and water provided ad libitum. The experiments were conducted in compliance with legislation for the protection of animals used for scientific purposes (Directive 2010/63/EU) and under Tampere University license EKS-2018 (issued 12 April 2018).

\subsection{Mouse Skin Sample Culture}

After euthanization, the back skin of the mice was shaved and a full thickness skin sample (diameter of $6 \mathrm{~mm}$ ) for each experimental condition was removed from the back skin and cultured in Dulbecco's Modified Eagle Medium (DMEM, Lonza, Bazel, Switzerland) containing $0.03 \mathrm{mM} \mathrm{Ca}^{2+}, 4 \mathrm{mM}$ L-glutamine, $250 \mathrm{ng} / \mathrm{mL}$ amphotericin $\mathrm{B}, 10 \%$ heatinactivated fetal bovine serum, $100 \mathrm{U} / \mathrm{mL}$ penicillin and $100 \mathrm{mg} / \mathrm{mL}$ streptomycin (all from Gibco, Waltham, MA, USA and Invitrogen, Carlsbad, CA, USA). The skin samples were incubated with or without TNF $(20 \mathrm{ng} / \mathrm{mL})$ for $21 \mathrm{~h}$ and the culture media were collected for further measurements.

\subsection{Western Blot Measurements}

At the end of the experiments, samples were collected and TRPA1 immunoprecipitation and Western blot measurements were carried out as described previously [6]. In brief, HaCaT keratinocytes were cultured on 6-well plates. After $48 \mathrm{~h}$ of treatment with or without TNF $(20 \mathrm{ng} / \mathrm{mL})$, total protein was extracted. The extract from six wells was 
pooled to form one sample, and equal amount of each sample was subjected to TRPA1 immunoprecipitation. TRPA1 antibody SAB2105082 ( $2 \mu \mathrm{g} / \mathrm{sample}$; Sigma-Aldrich) was added and the samples were incubated for $1 \mathrm{~h}$ at $4{ }^{\circ} \mathrm{C}$ in a rotator and thereafter Protein A/G PLUS-Agarose (sc-2003, Santa Cruz Biotechnology) was used to separate the immunocomplexes according to the manufacturer's instructions. Afterwards, Western blot analysis was carried out as described previously [6] using the TRPA1 antibody NB110-40763 (Novus Biologicals, LCC, Littleton, CO, USA) and the goat antirabbit HRP-conjugate (sc-2004, Santa Cruz Biotechnology) as the primary and secondary antibody, respectively.

\subsection{Fluo 3-AM Measurements}

Intracellular $\mathrm{Ca}^{2+}$ measurements were carried out using Fluo 3-AM as described previously [18]. HaCaT cells were first loaded for $30 \mathrm{~min}$ with $4 \mu \mathrm{M}$ fluo-3-acetoxymethyl ester (Fluo 3-AM, Millipore Sigma) and $0.08 \%$ Pluronic F- $127^{\circledR}$ in Hanks' balanced salt solution (HBSS, Lonza, Verviers, Belgium) containing $1 \mathrm{mg} / \mathrm{mL}$ bovine serum albumin, $2.5 \mathrm{mM}$ probenecid and $25 \mathrm{mM}$ HEPES pH 7.2 (all from Millipore Sigma). Thereafter, free intracellular $\mathrm{Ca}^{2+}$ levels were analyzed using Victor3 1420 multilabel counter (Perkin Elmer, Waltham, MA, USA) at 485/535 nm (for excitation/emission, respectively). HaCaT cells were preincubated with HC-030031 $(100 \mu \mathrm{M})$ or vehicle for $30 \mathrm{~min}$ before the TRPA1 agonist allyl isothiocyanate (AITC; $50 \mu \mathrm{M}$, Sigma-Aldrich) was added. The measurements were continued for $30 \mathrm{~s}$.

\subsection{Immunoassay}

MCP- 1 concentrations in the cell and tissue culture media were determined by enzymelinked immunosorbent assay (ELISA) with reagents purchased from R\&D Systems Europe Ltd., Abingdon, UK.

\subsection{RNA Extraction and Quantitative RT-PCR}

RNA was extracted and quantitative reverse transcription polymerase chain reaction (RT-PCR) was carried out as described previously [6].

\subsection{Statistical Analysis}

Data were analyzed using Graph-Pad InStat version 3.00 and Graph-Pad Prism version 5.02 softwares (GraphPad Software, San Diego, CA, USA). The results are presented as mean + standard error of the mean (SEM). One-way ANOVA and repeated measures two-way ANOVA with Bonferroni's multiple comparison test were used in the statistical analyses as indicated in figure legends.

Author Contributions: S.L., M.H. and E.M. contributed to the design of the study and the acquisition, analysis and interpretation of the data. E.M. supervised the study. S.L. drafted the manuscript and all authors revised the manuscript critically for important intellectual content and have approved the final version of the manuscript for submission. All authors have read and agreed to the published version of the manuscript.

Funding: The study was supported by grants from The Academy of Finland; Research Foundation of Rheumatic Diseases, Finland; Tampere Tuberculosis Foundation; and Competitive State Research Financing of the Expert Responsibility Area of Tampere University Hospital. The funding bodies had no role in the design of the study, or in the collection, analysis, and interpretation of data, or in the writing of the manuscript.

Institutional Review Board Statement: The study was conducted according to the guidelines of the Declaration of Helsinki, and approved by the Directive 2010/63/EU and under Tampere University license EKS-2018, issued 12 April 2018.

Informed Consent Statement: Not applicable; the study was based on cell culture and animal experiments.

Data Availability Statement: All data is included in the manuscript. 
Acknowledgments: We wish to thank Meiju Kukkonen and Salla Hietakangas for their excellent technical assistance.

Conflicts of Interest: The authors declare no conflict of interest.

\section{References}

1. Zygmunt, P.M.; Högestätt, E.D. Trpa1. Handb. Exp. Pharmacol. 2014, 222, 583-630. [PubMed]

2. Chen, J.; Joshi, S.K.; di Domenico, S.; Perner, R.J.; Mikusa, J.P.; Gauvin, D.M.; Segreti, J.A.; Han, P.; Zhang, X.-F.; Niforatos, W.; et al. Selective blockade of TRPA1 channel attenuates pathological pain without altering noxious cold sensation or body temperature regulation. Pain 2011, 152, 1165-1172. [CrossRef] [PubMed]

3. Bautista, D.M.; Jordt, S.-E.; Nikai, T.; Tsuruda, P.R.; Read, A.J.; Poblete, J.; Yamoah, E.N.; Basbaum, A.I.; Julius, D. TRPA1 Mediates the Inflammatory Actions of Environmental Irritants and Proalgesic Agents. Cell 2006, 124, 1269-1282. [CrossRef] [PubMed]

4. Gouin, O.; l'Herondelle, K.; Lebonvallet, N.; le Gall-Ianotto, C.; Sakka, M.; Buhé, V.; Plée-Gautier, E.; Carré, J.-L.; Lefeuvre, L.; Misery, L.; et al. TRPV1 and TRPA1 in cutaneous neurogenic and chronic inflammation: Pro-inflammatory response induced by their activation and their sensitization. Protein Cell 2017, 8, 644-661. [CrossRef]

5. Hatano, N.; Itoh, Y.; Suzuki, H.; Muraki, Y.; Hayashi, H.; Onozaki, K.; Wood, I.C.; Beech, D.J.; Muraki, K. Hypoxia-Inducible Factor-1alpha (HIF1alpha) Switches on Transient Receptor Potential Ankyrin Repeat 1 (TRPA1) Gene Expression Via a Hypoxia Response Element-Like Motif to Modulate Cytokine Release. J. Biol. Chem. 2012, 287, 31962-31972. [CrossRef]

6. Nummenmaa, E.; Hämäläinen, M.; Moilanen, L.J.; Paukkeri, E.L.; Nieminen, R.M.; Moilanen, T.; Vuolteenaho, K.; Moilanen, E. Transient Receptor Potential Ankyrin 1 (TRPA1) is Functionally Expressed in Primary Human Osteo-arthritic Chondrocytes. Arthritis Res. Ther. 2016, 18, 185-194. [CrossRef]

7. Chen, J.; Hackos, D.H. TRPA1 as a Drug Target-Promise and Challenges. Naunyn Schmiedebergs Arch. Pharmacol. 2015, 388, 451-463. [CrossRef]

8. Jordt, S.; Bautista, D.M.; Chuang, H.; McKemy, D.D.; Zygmunt, P.M.; Högestätt, E.D.; Meng, I.D.; Julius, D. Mustard Oils and Cannabinoids Excite Sensory Nerve fibres through the TRP Channel ANKTM1. Nature 2004, 427, 260-265. [CrossRef] [PubMed]

9. Macpherson, L.J.; Geierstanger, B.H.; Viswanath, V.; Bandell, M.; Eid, S.R.; Hwang, S.; Patapoutian, A. The Pungency of Garlic: Activation of TRPA1 and TRPV1 in Response to Allicin. Curr. Biol. 2005, 15, 929-934. [CrossRef]

10. Bessac, B.F.; Sivula, M.; von Hehn, C.A.; Escalera, J.; Cohn, L.; Jordt, S. TRPA1 is a Major Oxidant Sensor in Murine Airway Sensory Neurons. J. Clin. Investig. 2008, 118, 1899-1910. [CrossRef]

11. Andersson, D.A.; Gentry, C.; Moss, S.; Bevan, S. Transient Receptor Potential A1 is a Sensory Receptor for Multiple Products of Oxidative Stress. J. Neurosci. 2008, 28, 2485-2494. [CrossRef]

12. Taylor-Clark, T.E.; Ghatta, S.; Bettner, W.; Undem, B.J. Nitrooleic Acid, an Endogenous Product of Nitrative Stress, Activates Nociceptive Sensory Nerves via the Direct Activation of TRPA1. Mol. Pharmacol. 2009, 75, 820-829. [CrossRef]

13. Takahashi, N.; Mori, Y. TRP Channels as Sensors and Signal Integrators of Redox Status Changes. Front. Pharmacol. 2011, 2, 58. [CrossRef] [PubMed]

14. Bandell, M.; Story, G.M.; Hwang, S.W.; Viswanath, V.; Eid, S.R.; Petrus, M.J.; Earley, T.J.; Patapoutian, A. Noxious Cold Ion Channel TRPA1 is Activated by Pungent Compounds and Bradykinin. Neuron 2004, 41, 849-857. [CrossRef]

15. Dai, Y.; Wang, S.; Tominaga, M.; Yamamoto, S.; Fukuoka, T.; Higashi, T.; Kobayashi, K.; Obata, K.; Yamanaka, H.; Noguchi, K. Sensitization of TRPA1 by PAR2 contributes to the sensation of inflammatory pain. J. Clin. Investig. 2007, 117, 1979-1987. [CrossRef] [PubMed]

16. Wang, S.; Dai, Y.; Fukuoka, T.; Yamanaka, H.; Kobayashi, K.; Obata, K.; Cui, X.; Tominaga, M.; Noguchi, K. Phospholipase C and protein kinase A mediate bradykinin sensitization of TRPA1: A molecular mechanism of inflammatory pain. Brain 2008, 131, 1241-1251. [CrossRef] [PubMed]

17. Meents, J.E.; Fischer, M.J.M.; McNaughton, P.A. Sensitization of TRPA1 by Protein Kinase A. PLoS ONE 2017, 12, e0170097. [CrossRef] [PubMed]

18. Moilanen, L.J.; Hämäläinen, M.; Lehtimaki, L.; Nieminen, R.M.; Muraki, K.; Moilanen, E. Pinosylvin Inhibits TRPA1-Induced Calcium Influx in Vitro and TRPA1-Mediated Acute Paw Inflammation in Vivo. Basic Clin. Pharmacol. Toxicol. 2016, 118, 238-242. [CrossRef] [PubMed]

19. Moilanen, L.J.; Laavola, M.; Kukkonen, M.; Korhonen, R.; Leppanen, T.; Högestätt, E.D.; Zygmunt, P.M.; Nieminen, R.M.; Moilanen, E. TRPA1 Contributes to the Acute Inflammatory Response and Mediates Carrageenan-Induced Paw Edema in the Mouse. Sci. Rep. 2012, 2, 380. [CrossRef]

20. Moilanen, L.J.; Hämäläinen, M.; Lehtimaki, L.; Nieminen, R.M.; Moilanen, E. Urate Crystal Induced Inflammation and Joint Pain are Reduced in Transient Receptor Potential Ankyrin 1 Deficient Mice-Potential Role for Transient Receptor Potential Ankyrin 1 in Gout. PLoS ONE 2015, 10, e0117770. [CrossRef] [PubMed]

21. Trevisan, G.; Hoffmeister, C.; Rossato, M.F.; Oliveira, S.M.; Silva, M.A.; Silva, C.R.; Fusi, C.; Tonello, R.; Minocci, D.; Guerra, G.P. TRPA1 Receptor Stimulation by Hydrogen Peroxide is Critical to Trigger Hyperalgesia and Inflammation in a Model of Acute Gout. Free Radic. Biol. Med. 2014, 72, 200-209. [CrossRef]

22. Moilanen, L.J.; Hämäläinen, M.; Nummenmaa, E.; Ilmarinen, P.; Vuolteenaho, K.; Nieminen, R.M.; Lehtimaki, L.; Moilanen, E. Monosodium Iodoacetate-Induced Inflammation and Joint Pain are Reduced in TRPA1 Deficient Mice-Potential Role of TRPA1 in Osteoarthritis. Osteoarthr. Cartil. 2015, 23, 2017-2026. [CrossRef] 
23. Liu, B.; Escalera, J.; Balakrishna, S.; Fan, L.; Caceres, A.I.; Robinson, E.; Sui, A.; McKay, M.C.; McAlexander, M.A.; Herrick, C.A.; et al. TRPA1 controls inflammation and pruritogen responses in allergic contact dermatitis. FASEB J. 2013, 27, 3549-3563. [CrossRef]

24. Kang, J.; Ding, Y.; Li, B.; Liu, H.; Yang, X.; Chen, M. TRPA1 Mediated Aggravation of Allergic Contact Dermatitis Induced by DINP and Regulated by NF-кB Activation. Sci. Rep. 2017, 7, 43586. [CrossRef]

25. Oh, M.-H.; Oh, S.Y.; Lu, J.; Lou, H.; Myers, A.C.; Zhu, Z.; Zheng, T. TRPA1-Dependent Pruritus in IL-13-Induced Chronic Atopic Dermatitis. J. Immunol. 2013, 191, 5371-5382. [CrossRef]

26. Cevikbas, F.; Wang, X.; Akiyama, T.; Kempkes, C.; Savinko, T.; Antal, A.; Kukova, G.; Buhl, T.; Ikoma, A.; Buddenkotte, J.; et al. A sensory neuron-expressed IL-31 receptor mediates T helper cell-dependent itch: Involvement of TRPV1 and TRPA1. J. Allergy Clin. Immunol. 2014, 133, 448-460.e7. [CrossRef]

27. Wilson, S.R.; Nelson, A.M.; Batia, L.; Morita, T.; Estandian, D.; Owens, D.M.; Lumpkin, E.A.; Bautista, D.M. The Ion Channel TRPA1 Is Required for Chronic Itch. J. Neurosci. 2013, 33, 9283-9294. [CrossRef]

28. Kemény, Á.; Kodji, X.; Horváth, S.; Komlódi, R.; Szőke, É.; Sándor, Z.; Perkecz, A.; Gyömörei, C.; Sétáló, G.; Kelemen, B. TRPA1 Acts in a Protective Manner in Imiquimod-Induced Psoriasiform Dermatitis in Mice. J. Investig. Dermatol. 2018, 138, 1774-1784. [CrossRef]

29. Jain, A.; Brnneke, S.; Kolbe, L.; Stb, F.; Wenck, H.; Neufang, G. TRP-Channel-Specific Cutaneous Eicosanoid Release Patterns. Pain 2011, 152, 2765-2772. [CrossRef]

30. Atoyan, R.; Shander, D.; Botchkareva, N.V. Non-Neuronal Expression of Transient Receptor Potential Type A1 (TRPA1) in Human Skin. J. Investig. Dermatol. 2009, 129, 2312-2315. [CrossRef]

31. Jaquemar, D.; Schenker, T.; Trueb, B. An Ankyrin-like Protein with Transmembrane Domains Is Specifically Lost after Oncogenic Transformation of Human Fibroblasts. J. Biol. Chem. 1999, 274, 7325-7333. [CrossRef]

32. Story, G.M.; Peier, A.M.; Reeve, A.J.; Eid, S.R.; Mosbacher, J.; Hricik, T.R.; Earley, T.J.; Hergarden, A.C.; Andersson, D.A.; Hwang, S.W.; et al. ANKTM1, a TRP-like Channel Expressed in Nociceptive Neurons, Is Activated by Cold Temperatures. Cell 2003, 112, 819-829. [CrossRef]

33. Nilius, B.; Appendino, G.; Owsianik, G. The Transient Receptor Potential Channel TRPA1: From Gene to Pathophysiology. Pflgers Arch. Eur. J. Physiol. 2012, 464, 425-458. [CrossRef] [PubMed]

34. Bellono, N.W.; Kammel, L.G.; Zimmerman, A.L.; Oancea, E. UV light phototransduction activates transient receptor potential A1 ion channels in human melanocytes. Proc. Natl. Acad. Sci. USA 2013, 110, 2383-2388. [CrossRef] [PubMed]

35. Mukhopadhyay, I.; Gomes, P.; Aranake, S.; Shetty, M.; Karnik, P.; Damle, M.; Kuruganti, S.; Thorat, S.; Khairatkar-Joshi, N. Expression of functional TRPA1 receptor on human lung fibroblast and epithelial cells. J. Recept. Signal Transduct. 2011, 31, 350-358. [CrossRef] [PubMed]

36. Moilanen, L.J.; Hämäläinen, M.; Ilmarinen, P.; Kankaanranta, H.; Nieminen, R.M.; Moilanen, E.; Lehtimäki, L. Transient Receptor Potential Ankyrin 1 Enhances Ovalbumin-Induced Acute Allergic Inflammation in Murine Models. Int. Arch. Allergy Immunol. 2019, 178, 1-10. [CrossRef] [PubMed]

37. Engel, M.A.; Leffler, A.; Niedermirtl, F.; Babes, A.; Zimmermann, K.; Filipović, M.R.; Izydorczyk, I.; Eberhardt, M.; Kichko, T.I.; Mueller-Tribbensee, S.M. TRPA1 and Substance P Mediate Colitis in Mice. Gastroenterology 2011, 141, 1346-1358. [CrossRef] [PubMed]

38. Sbidian, E.; Chaimani, A.; Garcia-Doval, I.; Do, G.; Hua, C.; Mazaud, C.; Droitcourt, C.; Hughes, C.; Ingram, J.R.; Naldi, L. Systemic Pharmacological Treatments for Chronic Plaque Psoriasis: A Network Meta-analysis. Cochrane Database Syst. Rev. 2017, 12, CD011535. [CrossRef]

39. Zhang, Q.; Lenardo, M.J.; Baltimore, D. 30 Years of NF-kB: A Blossoming of Relevance to Human Pathobiology. Cell 2017, 168, 37-57. [CrossRef] [PubMed]

40. Arthur, J.S.C.; Ley, S.C. Mitogen-activated protein kinases in innate immunity. Nat. Rev. Immunol. 2013, 13, 679-692. [CrossRef]

41. Gutfreund, K.; Bienias, W.; Szewczyk, A.; Kaszuba, A. Topical calcineurin inhibitors in dermatology. Part I: Properties, method and effectiveness of drug use. Adv. Dermatol. Allergol. 2013, 3, 165-169. [CrossRef] [PubMed]

42. Al-Daraji, W.I.; Grant, K.R.; Ryan, K.; Saxton, A.; Reynolds, N.J. Localization of Calcineurin/NFAT in Human Skin and Psoriasis and Inhibition of Calcineurin/NFAT Activation in Human Keratinocytes by Cyclosporin A. J. Investig. Dermatol. 2002, 118, 779-788. [CrossRef]

43. Mammucari, C.; di Vignano, A.T.; Sharov, A.A.; Neilson, J.; Havrda, M.C.; Roop, D.R.; Botchkarev, V.A.; Crabtree, G.R.; Dotto, G.P. Integration of Notch 1 and Calcineurin/NFAT Signaling Pathways in Keratinocyte Growth and Differentiation Control. Dev. Cell 2005, 8, 665-676. [CrossRef] [PubMed]

44. Jans, R.; Mottram, L.; Johnson, D.L.; Brown, A.M.; Sikkink, S.; Ross, K.; Reynolds, N.J. Lysophosphatidic Acid Promotes Cell Migration through STIM1- and Orai1-Mediated $\mathrm{Ca}^{2+}$ i Mobilization and NFAT2 Activation. J. Investig. Dermatol. 2013, 133, 793-802. [CrossRef] [PubMed]

45. Mehta, A.B.; Nadkarni, N.J.; Patil, S.P.; Godse, K.V.; Gautam, M.; Agarwal, S. Topical Corticosteroids in Dermatology. Indian J. Dermatol. Venereol. Leprol. 2016, 82, 371. [CrossRef]

46. Nummenmaa, E.; Hämäläinen, M.; Moilanen, L.J.; Moilanen, T.; Vuolteenaho, K.; Moilanen, E. TRPA1 Expression is Downregulated by Dexamethasone and Aurothiomalate in Human Chondrocytes: TRPA1 as a Novel Factor and Drug Target in Arthritis. RMD Open 2017, 3, e000556. [CrossRef] [PubMed] 
47. Bootman, M.D. Calcium Signaling. Cold Spring Harb. Perspect. Biol. 2012, 4, a011171. [CrossRef] [PubMed]

48. Deshmane, S.L.; Kremlev, S.; Amini, S.; Sawaya, B.E. Monocyte Chemoattractant Protein-1 (MCP-1): An Over-view. J. Interferon Cytokine Res. 2009, 29, 313-326. [CrossRef]

49. Behfar, S.; Hassanshahi, G.; Nazari, A.; Khorramdelazad, H. A Brief Look at the Role of Monocyte Chemoattractant Protein-1 (CCL2) in the Pathophysiology of Psoriasis. Cytokine 2018, 110, 226-231. [CrossRef]

50. Wilson, V.G. Growth and Differentiation of HaCaT Keratinocytes. Adv. Struct. Saf. Stud. 2013, 1195, 33-41. [CrossRef] 